\title{
Effects of Food Color Additiveson Antioxidant Functions and Bioelement Contents of Liver, Kidney and Brain Tissues in Rats
}

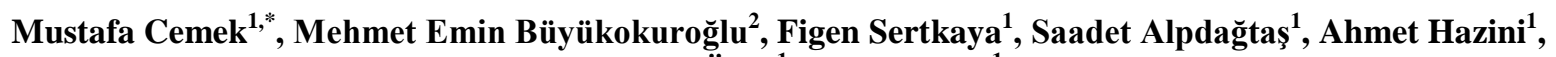 \\ Abdullah Önül ${ }^{1}$, Sadık Göneş ${ }^{1}$ \\ ${ }^{1}$ Department of Bioengineering, Faculty of Chemistry-Metallurgy, Yildiz Technical University, Istanbul, Turkey \\ ${ }^{2}$ Department of Pharmacology, Faculty of Medicine, Sakarya University, Sakarya, Turkey \\ *Corresponding author: mcemek@yahoo.com
}

Received July 22, 2014; Revised September 17, 2014; Accepted September 24, 2014

\begin{abstract}
A number of chemical food coloring additives are added during processing to improve the appearance of thef oods and drinks. Tartrazine and carmoisine are organic azo dyes widely used in food products, drugs and cosmetics. The present study conducted to evaluate the effects of these food coloring additives via determination of bioelements, oxidant and antioxidant levels in liver, kidney, brain tissues and measurement of antioxidantvitamin levels in serum of rats. Animals were administered in high and low doses of tartrazine and carmoisine for a period of $15 \mathrm{~d}$ followed by blood and tissue sample collection for determination of antioxidant vitamin levels in serum and reduced glutathione (GSH), malondialdehyde (MDA) and most important trace and major bioelement contents in tissues. We did not observed any statistically significant changes in antioxidant vitamin levels in serum and in tissue MDA and GSH contents. But we determined the some significant changes about levels of bioelements in rats' liver, kidney and brain tissues exposed to the tartrazine and carmoisine. We concluded that tartrazine and carmoisine affect and alter bioelements levels in vital organs e.g. liver, kidney and brain. This issue should be considered by food manufacturers and consumers always.
\end{abstract}

Keywords: food color, Carmoisine, Tartrazin, Oxidant, Antioxidant, Bioelement

Cite This Article: Mustafa Cemek, Mehmet Emin Büyükokuroğlu, Figen Sertkaya, Saadet Alpdağtaş, Ahmet Hazini, Abdullah Önül, and Sadık Göneş, "Effects of Food Color Additiveson Antioxidant Functions and Bioelement Contents of Liver, Kidney and Brain Tissues in Rats." Journal of Food and Nutrition Research, vol. 2, no. 10 (2014): 686-691. doi: 10.12691/jfnr-2-10-6.

\section{Introduction}

Food additives have extremely important role to meet the needs of growing population during production and presentation of plentiful, tasty and nutritious food (Gao et al., 2011). Whether synthetic or natural food additives may be used as flavoring or coloring stuffs (Sayed et al., 2012). Colorants provide an aesthetic appearance to food stuffs for preferred by consumers (Amin et al., 2010)

Food colorants are generally used as mixtures of two or more dyes to form different food colors. (Sharma et al., 2008) Azo dyes have a wide range of applications in the textile, leather, paper, food, pharmaceutical and cosmetic industries (Mansour et al., 2007). Azo colors are characterized by azo groups $(-\mathrm{N}=\mathrm{N})$ bound to aromatic rings in their molecular structures (Demirkol et al., 2012). Tartrazine and Carmoisine are used as food colorants in different industries. Tartrazine is an azo dye and it provides lemon yellow color. Most of food stuffs and some of non food products include tartrazine as a colorant like chips, soft drinks, cakes, ice cream, soaps, shampoos, medicinal capsules, drugs. Carmoisine belongs to azo dye group, too. It is used as a red colorant by various industries (Amin et al., 2010).

To classify a dye as a harmful agent to humans depends on its ability to reductively cleave and generate aromatic amines which have carcinogenic effect and can accumulate food chains during interaction with body secretions such as saliva and gastric secretions. Azo dyes can be reduced to aromatic amines by intestinal microflora and perhaps by mammalian azo reductase in the liver or in the intestinal wall following ingestion (Chequer et al., 2011a). If the azo dyes are reduced completely to aromatic amines, P450 enzymes oxidize these aromatic amines to N-hydroxy derivatives (Demirkol et al., 2012). This kind of biotransformation can occur in a wide variety of mammalian species including humans (Chequer et al., 2011a).

Shortly, the mutagenic, carcinogenic and toxic effects of azo dyes stem from the direct effect of the dye or indirectly from the reductive biotransformation of the azo bond during its metabolism (Chequer et al. 2011b). After prolonged use many of azo dyes can cause some diseases such as anemia, indigestion, pathological lesions in the brain, liver, kidney and spleen, tumor and cancer, growth deficiency, mental deficiency, anomaly in off springs and 
eye defects resulting in blindness and allergic reactions as nettle rash and asthma (Sayed et al., 2012).

Bio-elements (trace and major elements) are vital requirements of an organism to maintain its physiological functions. Several bioelements have important roles in cells to perform its functions properly. They are responsible for crucial pathways in redox reactions, cell membranes, stability of biological molecules and control biological processes (Cemek et al., 2010).

Amin et al. have concluded that tartrazine affected adversely and altered biochemical markers such as antioxidant enzymes in vital tissues (Amin et al., 2010). Tartrazine also inflamed the stomach lining (increased the number of lymphocytes and eosinophils) of rats when given in the diet for a prolonged period of time (Moutinho et al., 2007). According to our knowledge, there are no data about the tissue levels of trace and major element in food color additives.

The aim of present study was to determine the effects of two azo dyes, tartrazine and carmoisine (commonly used food colors), on rat serum and liver, kidney and brain tissues by measuring some antioxidant biomarkers and bioelement levels.

\section{Materials and Methods}

\subsection{Chemicals}

Sodium chloride, sodium dihydrogen phosphate, sodium hydroxide, meta-phosphoric acid, sodium citrate, phosphoric acid, copper(II) sulfate, hydrazine sulfate, sodium acetate, perchloric acid, acetic acid, sulfuric acid, thiourea, hydrogen peroxide, GSH, thiobarbituric acid, phosphate buffer, butylated hydroxytoluene, trichloroacetic acid, EDTA, [5,5-dithiobis-(2nitrobenzoicacid)], disodium hydrogen phosphate, phenylenediamine, sodium azide,2,4dinitrophenylhydrazine, ethanol, hexane, potassium phosphate, sodium phosphate dibasic dihydrate, hydrogen peroxide, ethanol, sodium chloride, nitric acid, perchloric acid, suprapur Inductively Coupled Plasma-Optical Emission Spectroscopy (ICP-OES) multielement standard solutions were purchased from Merck. All other chemicals and reagents used in this study were of analytical grade.

\subsection{Animals}

Male Wistar albino rats weighing 150-210 g were housed under standard laboratory conditions and were allowed free access to food and water. The investigation was conducted in accordance with the Guide for the Care and Use of Laboratory Animals published by the US National Institutes of Health (NIH Publication no. 85-23, revised 1996), and approval has been received from our institutional Animal Ethics Committee.

\subsection{Experimental Design}

Fifty rats were divided into five groups. Control group did not receive any agent. Three $\mathrm{mg} / \mathrm{kg}$ and $15 \mathrm{mg} / \mathrm{kg}$ doses of tartrazine were administered to the low tartrazine and high tartrazine groups by gavage, respectively, throughout 15 days. Half a $\mathrm{mg} / \mathrm{kg}$ and $2.5 \mathrm{mg} / \mathrm{kg}$ doses of carmoisine were administered to the low carmoisine and high carmoisine groups by gavage, respectively, throughout 15 days. All rats were anesthetized with ketaminehydrochloride (100 mg/kg, i.p.). Then, the animals were sacrificed under anesthesia, blood collected by injection from heart into heparinized tubes and the brain, liver, kidney were removed and rapidly placed in a deep freezer at $-70^{\circ} \mathrm{C}$ until the time of analysis.

\subsection{Biochemical analysis}

At the end of the experiment, all animals were sacrificed under ether anesthesia. Blood samples for the biochemical analysis were collected by cardiac puncture. Whole blood was collected into heparinized tubes, and reduced glutathione (GSH), malondialdehyde (MDA) levels were studied on the same day of admission. Blood was also collected into a polystyrenemicrotube, and after clotting, centrifuged at $1000 \mathrm{~g}$ for $10 \mathrm{~min}$ at $+4^{\circ} \mathrm{C}$, and the serum was removed using EDTA-washed Pasteur pipettes. The studied tissues were homogenized in tenfold volume of physiological saline solution by using a homogenizer (Ultra-Turrax T25, IKA; Werke 24,000 r.p.m.; Germany). The homogenate was centrifuged at $10,000 \mathrm{~g}$ for $1 \mathrm{~h}$ to remove debris. Clear upper supernatant was taken, and tissue analyses were carried out in this fraction. All the procedures were performed at $+4^{\circ} \mathrm{C}$ throughout the experiments. The serum and tissue samples were stored in polystyrene plastic tube at $-70^{\circ} \mathrm{C}$ until the time of analysis. Serumretinol, $\beta$-carotene and $\alpha$-tocopherol were studied by spectrophotometer (Jenway 6305 UV/vis). MDA (as an important indicator of oxidative stress) levels were measured according to a method of Jain et al. (Jain et al., 1989). The principle of the method is based on the spectrophotometric measurement of the color that occurred during the reaction of thiobarbituric acid with MDA. Concentrations of thiobarbituric acid reactive substances were calculated by the absorbance coefficient of malondialdehyde-thiobarbituric acid complex and expressed in $\mathrm{nmol} / \mathrm{ml}$. GSH concentration also was measured by a spectrophotometric method (Beutler et al., 1963). After lysing whole blood and removal of precipitate, disodium hydrogen phosphate and DTNB solution were added and color formed was read at $412 \mathrm{~nm}$. The results were expressed in $\mathrm{mg} / \mathrm{dl}$. The levels of $\beta$ carotene at $425 \mathrm{~nm}$ and vitamin A (retinol) at $325 \mathrm{~nm}$ were detected after the reaction of serum isto ethanol is to hexane at the ratio of $1: 1: 3$, respectively (Suzuki and Katoh, 1990). VitaminE ( $\alpha$-tocopherol) was analyzed colorimetrically with 2,4,6-tripridyl-s-triazin and ferric chloride after the extraction with absolute ethanol and xylene (Martinek, 1964).

\subsection{Determination of Tissue Concentrations of Trace and Major Elements}

The studied tissues were homogenized in tenfold volume of physiological saline solution by using a homogenizer (Ultra-Turrax T25, IKA; Werke 24,000 r.p.m.; Germany). The homogenate was centrifuged at $10,000 \times g$ for $1 \mathrm{~h}$ to remove debris. Clear upper supernatant was taken, and tissue analyses were carried out in this fraction. All the procedures were performed at $+4^{\circ} \mathrm{C}$ throughout the experiments. All the plastic containers were previously washed in $10 \% \mathrm{HNO}_{3}$ 
(ultrapure grade) and then repeatedly rinsed with ultra water. Decomposition of the organic matrix in the tissue samples were performed by using a microwave oven. A Milestone Start D (Italy) microwave oven equipped with a Pro 24 High Throughput Rotor and a temperature control programme was used to digest simultaneously 24 samples of tissue in one cycle. The rest of the elements were determined after mineralization of the samples. The tissue samples of exactly $0.1 \mathrm{~g}$ were weighed (wet weight) and put in high-pressure Teflon vessels and added with $3 \mathrm{ml}$ of concentrated $\mathrm{HNO}_{3}, 1 \mathrm{ml}$ of $\mathrm{H}_{2} \mathrm{O}_{2}$ and $0.5 \mathrm{ml} \mathrm{HClO}_{4}$ (ultrapure, Merck, Germany). The Teflon vessels were then sealed with a Teflon lid and put into the steel bombs which were sealed with exactly the same momentum. The mixture in the bombs was heated in a microwave oven according to the following sequence (temperature/time): $90^{\circ} \mathrm{C} / 15 \mathrm{~min}, 120^{\circ} \mathrm{C} / 15 \mathrm{~min}, 140^{\circ} \mathrm{C} / 60 \mathrm{~min}, 150^{\circ} \mathrm{C} / 60$ min. After cooling to room temperature, this solution was quantitatively transferred and adjusted in a flask to 10 mlwith 18.2 M $\Omega . c m$ ultra water (Milipore DirectQ UV, Japan). Trace and major element concentrations in the digest were determined by ICP-OES (Spectro Genesis, Germany). The operating conditions of the ICP-OES are given in Table 1. Accuracy of the analysis was verified by the determination of the mineral content of the ICP-OES multielement standard obtained from Merck (Germany).

Table 1. ICP-OES apparatus specifications and analytical conditions for the determination of elements

\begin{tabular}{|c|c|}
\hline Instrument & Spectro Genesis Fee, Germany \\
\hline Nebulizer & Cross Flow \\
\hline Plasma Power & $1380 \mathrm{~W}$ \\
\hline Coolnat Flow & $14.00 \mathrm{~L} / \mathrm{min}$ \\
\hline Auxiliary Flow & $1.00 \mathrm{~L} / \mathrm{min}$ \\
\hline Nebulizer Flow & $1.05 \mathrm{~L} / \mathrm{min}$ \\
\hline Optic Flush & Normal \\
\hline Measure Strategy & Best SNR \\
\hline Reply & 2 \\
\hline Measure Time & $90 \mathrm{~s}$ \\
\hline Flush Time & $40 \mathrm{~s}$ \\
\hline
\end{tabular}

\subsection{Statistical Analysis}

All data were expressed as the mean \pm standard deviation of the mean. Differences among control and the four experimentalgroups were considered statistically significant when the $p$ value was $<0.05$ using one-way analysis of variance (ANOVA), followed by a post-hoc Dunnett's test. Statistical tests were performed using SPSS version 12.0 PL for Windows.

Table 2. Serum antioxidant vitamin levels in the study and control groups

\begin{tabular}{|c|c|c|c|c|c|}
\hline Parameters & Control & Low tartrazine & High tartrazine & Low carmoisine & High carmoisine \\
\hline Retinol $(\mu \mathrm{g} / \mathrm{dl})$ & $59.397 \pm 2.12$ & $61.789 \pm 4.33$ & $62.709 \pm 3.63$ & $60.187 \pm 4.64$ & $62.102 \pm 4.92$ \\
\hline$\beta$-Carotene $(\mu \mathrm{g} / \mathrm{dl})$ & $17.456 \pm 0.84$ & $17.701 \pm 0.72$ & $17.885 \pm 0.65$ & $17.829 \pm 0.71$ & $17.497 \pm 0.65$ \\
\hline$\alpha$-tocopherol $(\mathrm{mg} / \mathrm{dl})$ & $0.924 \pm 0.26$ & $0.846 \pm 0.16$ & $0.971 \pm 0.46$ & $0.882 \pm 0.10$ & $0.808 \pm 0.16$ \\
\hline
\end{tabular}

$\beta$-carotene and retinol: vitamin $\mathrm{A}, \alpha$-tocopherol: vitamin $\mathrm{E}$

\section{Results}

\subsection{Retinol, $\beta$-carotene and $\alpha$-tocopherol Levels}

Antioxidant vitamin (retinol, $\beta$-carotene and $\alpha$ tocopherol) levels of control and experimental groups are presented in Table 2. Although there were some alterations in these antioxidant vitamin levels between control and experimental groups, none of these changes had any statistically significance $(p>0.05)$.

\subsection{MDA and GSH Levels in Tissues}

MDA and GSH levels in liver, kidney and brain in control and experimental groups are shown in the Table 3 and Table 4. Liver, kidney and brain tissue MDA and GSHlevelsin control and experimental groups were very close and there was no significant difference between groups $(p>0.05)$.

Table 3. Malondialdehyde (MDA) as lipid peroxidation marker levels (nmol/mg tissue) in tissues in the study and control groups

\begin{tabular}{|c|c|c|c|c|c|}
\hline \multicolumn{1}{|c|}{ Tissues } & Control & Low tartrazine & High tartrazine & Low carmoisine & High carmoisine \\
\hline Liver & $20.539 \pm 3.08$ & $21.557 \pm 3.09$ & $26.183 \pm 3.24$ & $17.116 \pm 1.58$ & $20.262 \pm 7.45$ \\
\hline Kidney & $53.199 \pm 8.59$ & $44.039 \pm 5.77$ & $63.561 \pm 9.52$ & $46.352 \pm 5.69$ & $46.674 \pm 6.99$ \\
\hline Brain & $108.102 \pm 11.59$ & $102.511 \pm 16.37$ & $110.104 \pm 24.63$ & $116.671 \pm 18.30$ & $111.832 \pm 6.39$ \\
\hline
\end{tabular}

Table 4. Reduced glutathione (GSH) levels (nmol/g tissue) in tissues in the study and control groups

\begin{tabular}{|c|c|c|c|c|c|}
\hline Tissues & Control & Low tartrazine & High tartrazine & Low carmoisine & High carmoisine \\
\hline Liver & $146.532 \pm 12.44$ & $150.361 \pm 8.91$ & $143.973 \pm 11.30$ & $144.411 \pm 11.45$ & $150.934 \pm 13.85$ \\
\hline Kidney & $139.991 \pm 10.91$ & $141.253 \pm 13.66$ & $138.380 \pm 11.06$ & $139.262 \pm 8.69$ & $142.854 \pm 10.19$ \\
\hline Brain & $151.354 \pm 9.26$ & $146.122 \pm 6.95$ & $144.921 \pm 10.07$ & $141.653 \pm 8.40$ & $146.554 \pm 8.59$ \\
\hline
\end{tabular}

\subsection{Trace and Major Elements in Tissues}

Liver tissue trace and major elements concentrations of the all groups are presented in Table 5. In high-dose carmoisine group, Ca level increased significantly compared to control group $(p<0.001)$. Similarly Cr level was statically higher than the control group $(p<0.05)$. The Fe concentrations were lower in the low-dose tartrazine, low-dose carmoisine and high-dose carmoisine groups than the control $(p<0.05)$. The Ga levels increased in all experimental groups except that low-dose tartrazine group $(p<0.05)$. While the Mn concentration was lower in lowdose carmoisine group $(p<0.01)$, Sr levels were higher in the high dose carmoisine group than the control $(p<0.05)$. Also, Zn levels decreased significantly compared to control group in high and low dose carmoisine group $(p<0.001)$. 
Table 5. Liver tissue concentrations ( $\mu \mathrm{g} / \mathrm{g}$ tissue) of trace and major elementsin the study and control groups

\begin{tabular}{|c|c|c|c|c|c|}
\hline Elements & Control & Low tartrazine & High tartrazine & Low carmoisine & High carmoisine \\
\hline Aluminum (Al) & $2.121 \pm 0.66$ & $1.518 \pm 0.17$ & $1.761 \pm 0.57$ & $1.519 \pm 0.34$ & $2.435 \pm 0.88$ \\
\hline Barium (Ba) & $0.172 \pm 0.04$ & $0.281 \pm 0.08$ & $0.245 \pm 0.16$ & $0.292 \pm 0.08$ & $0.258 \pm 0.07$ \\
\hline Beryllium (Be) & $0.346 \pm 0.06$ & $0.384 \pm 0.07$ & $0.374 \pm 0.08$ & $0.389 \pm 0.09$ & $0.381 \pm 0.07$ \\
\hline Calcium (Ca) & $79.173 \pm 10.06$ & $84.796 \pm 5.73$ & $79.821 \pm 3.74$ & $88.871 \pm 16.57$ & $113.40 \pm 22.20^{\mathrm{c}}$ \\
\hline Chromium (Cr) & $0.171 \pm 0.004$ & $0.178 \pm 0.005$ & $0.172 \pm 0.004$ & $0.177 \pm 0.008$ & $0.181 \pm 0.009^{\mathrm{a}}$ \\
\hline Copper (Cu) & $4.288 \pm 0.21$ & $4.0862 \pm 0.45$ & $4.605 \pm 0.43$ & $4.026 \pm 0.11$ & $4.019 \pm 0.15$ \\
\hline Iron (Fe) & $205.902 \pm 36.79$ & $154.451 \pm 27.42^{\mathrm{a}}$ & $178.423 \pm 45.92$ & $141.065 \pm 31.37^{\mathrm{a}}$ & $149.531 \pm 35.55^{\mathrm{a}}$ \\
\hline Gallium (Ga) & $1.048 \pm 0.02$ & $1.066 \pm 0.02$ & $1.078 \pm 0.02^{\mathrm{a}}$ & $1.075 \pm 0.01^{\mathrm{a}}$ & $1.079 \pm 0.02^{\mathrm{a}}$ \\
\hline Magnesium (Mg) & $212.64 \pm 3.79$ & $211.59 \pm 4.88$ & $218.28 \pm 3.34$ & $205.214 \pm 7.02$ & $211.953 \pm 3.18$ \\
\hline Manganese $(\mathrm{Mn})$ & $2.250 \pm 0.06$ & $2.136 \pm 0.23$ & $2.256 \pm 0.15$ & $1.815 \pm 0.52^{\mathrm{b}}$ & $2.190 \pm 0.08$ \\
\hline Selenium $(\mathrm{Se})$ & $1.920 \pm 0.26$ & $2.200 \pm 0.25$ & $1.972 \pm 0.17$ & $2.146 \pm 0.34$ & $1.712 \pm 0.18$ \\
\hline Strontium $(\mathrm{Sr})$ & $0.329 \pm 0.03$ & $0.399 \pm 0.05$ & $0.341 \pm 0.03$ & $0.418 \pm 0.12$ & $0.479 \pm 0.09^{\mathrm{a}}$ \\
\hline Zinc $(\mathrm{Zn})$ & $34.964 \pm 1.49$ & $32.583 \pm 2.03^{\mathrm{a}}$ & $34.524 \pm 1.33$ & $30.629 \pm 1.80^{\mathrm{c}}$ & $31.525 \pm 1.58^{\mathrm{c}}$ \\
\hline
\end{tabular}

${ }^{a}: p<0.05$ with respect to control

${ }^{\mathrm{b}}: p<0.01$ with respect to control

: $p<0.001$ with respect to control

\begin{tabular}{|c|c|c|c|c|c|}
\hline Elements & Control & Low tartrazine & High tartrazine & Low carmoisine & High carmoisine \\
\hline Aluminum (Al) & $2.129 \pm 0.82$ & $1.959 \pm 0.88$ & $1.625 \pm 0.59$ & $1.611 \pm 0.85$ & $1.658 \pm 0.62$ \\
\hline Barium $(\mathrm{Ba})$ & $0.543 \pm 0.22$ & $0.523 \pm 0.28$ & $0.301 \pm 0.16$ & $0.424 \pm 0.24$ & $0.276 \pm 0.17^{\mathrm{a}}$ \\
\hline Beryllium (Be) & $0.424 \pm 0.008$ & $0.431 \pm 0.013$ & $0.424 \pm 0.006$ & $0.429 \pm 0.005$ & $0.426 \pm 0.00449$ \\
\hline Calcium (Ca) & $94.916 \pm 14.99$ & $96.528 \pm 8.51$ & $102.032 \pm 15.42$ & $95.624 \pm 3.95$ & $95.497 \pm 6.21$ \\
\hline Chromium (Cr) & $0.183 \pm 0.008$ & $0.182 \pm 0.006$ & $0.178 \pm 0.006$ & $0.178 \pm 0.004$ & $0.176 \pm 0.003$ \\
\hline Copper $(\mathrm{Cu})$ & $6.476 \pm 0.91$ & $8.043 \pm 1.65^{\mathrm{a}}$ & $7.174 \pm 0.11$ & $9.265 \pm 0.87^{\mathrm{c}}$ & $9.748 \pm 1.05^{c}$ \\
\hline Iron $(\mathrm{Fe})$ & $65.428 \pm 6.52$ & $55.040 \pm 3.43^{b}$ & $60.451 \pm 5.25$ & $53.701 \pm 7.77^{b}$ & $63.158 \pm 4.98$ \\
\hline Gallium (Ga) & $1.079 \pm 0.03$ & $1.093 \pm 0.03$ & $1.063 \pm 0.02$ & $1.068 \pm 0.02$ & $1.067 \pm 0.01$ \\
\hline Magnesium (Mg) & $181.02 \pm 5.81$ & $184.59 \pm 7.85$ & $173.93 \pm 6.96$ & $186.69 \pm 5.79$ & $181.53 \pm 8.01$ \\
\hline Manganese (Mn) & $0.481 \pm 0.03$ & $0.468 \pm 0.04$ & $0.509 \pm 0.05$ & $0.572 \pm 0.07^{\mathrm{b}}$ & $0.542 \pm 0.04^{\mathrm{a}}$ \\
\hline Selenium (Se) & $2.451 \pm 0.28$ & $2.388 \pm 0.35$ & $2.621 \pm 0.32$ & $2.701 \pm 0.35$ & $2.755 \pm 0.19$ \\
\hline Strontium (Sr) & $0.308 \pm 0.05$ & $0.289 \pm 0.03$ & $0.375 \pm 0.11$ & $0.281 \pm 0.03$ & $0.295 \pm 0.02$ \\
\hline Zinc (Zn) & $23.502 \pm 1.12$ & $22.938 \pm 0.64$ & $21.959 \pm 0.79^{\mathrm{a}}$ & $23.120 \pm 0.88$ & $24.207 \pm 0.87$ \\
\hline
\end{tabular}

Table 7. Brain tissue concentrations ( $\mu \mathrm{g} / \mathrm{g}$ tissue) of trace and major elementsin the study and control groups

\begin{tabular}{|c|c|c|c|c|c|}
\hline Elements & Control & Low tartrazine & High tartrazine & Low carmoisine & High carmoisine \\
\hline Aluminum (Al) & $2.827 \pm 0.39$ & $1.567 \pm 0.41^{\mathrm{c}}$ & $1.690 \pm 0.29^{c}$ & $2.652 \pm 0.70$ & $3.137 \pm 0.32$ \\
\hline Barium (Ba) & $1.355 \pm 0.47$ & $0.662 \pm 0.52^{\mathrm{a}}$ & $0.519 \pm 0.19^{b}$ & $1.188 \pm 0.58$ & $1.342 \pm 0.28$ \\
\hline Beryllium (Be) & $0.445 \pm 0.005$ & $0.445 \pm 0.006$ & $0.452 \pm 0.003$ & $0.448 \pm 0.006$ & $0.446 \pm 0.006$ \\
\hline Calcium (Ca) & $143.01 \pm 29.91$ & $113.32 \pm 46.95$ & $92.972 \pm 24.73$ & $95.714 \pm 29.16$ & $128.29 \pm 49.13$ \\
\hline Chromium (Cr) & $0.191 \pm 0.01$ & $0.183 \pm 0.01$ & $0.193 \pm 0.04$ & $0.172 \pm 0.01$ & $0.171 \pm 0.01$ \\
\hline Copper (Cu) & $2.244 \pm 0.15$ & $2.338 \pm 0.17$ & $2.275 \pm 0.20$ & $2.016 \pm 0.04$ & $2.088 \pm 0.29$ \\
\hline Iron $(\mathrm{Fe})$ & $16.991 \pm 1.03$ & $16.072 \pm 1.06$ & $15.114 \pm 0.94^{\mathrm{a}}$ & $14.101 \pm 1.53^{\mathrm{c}}$ & $12.967 \pm 1.48^{\mathrm{c}}$ \\
\hline Gallium (Ga) & $1.149 \pm 0.03$ & $1.082 \pm 0.02^{\mathrm{a}}$ & $1.102 \pm 0.02^{\mathrm{a}}$ & $1.083 \pm 0.02^{\mathrm{a}}$ & $1.075 \pm 0.01^{\mathrm{a}}$ \\
\hline Magnesium (Mg) & $158.26 \pm 5.18$ & $151.27 \pm 4.54$ & $158.17 \pm 6.41$ & $148.21 \pm 5.43$ & $146.91 \pm 7.31$ \\
\hline Manganese (Mn) & $0.090 \pm 0.017$ & $0.085 \pm 0.06$ & $0.055 \pm 0.012$ & $0.056 \pm 0.028$ & $0.054 \pm 0.030$ \\
\hline Selenium (Se) & $1.002 \pm 0.18$ & $1.145 \pm 0.09$ & $1.079 \pm 0.14$ & $1.061 \pm 0.11$ & $1.079 \pm 0.21$ \\
\hline Strontium (Sr) & $0.565 \pm 0.11$ & $0.442 \pm 0.13$ & $0.381 \pm 0.03$ & $0.448 \pm 0.22$ & $0.548 \pm 0.22$ \\
\hline Zinc (Zn) & $13.890 \pm 0.49$ & $13.378 \pm 0.98$ & $14.899 \pm 0.44$ & $13.533 \pm 0.63$ & $14.231 \pm 2.50$ \\
\hline
\end{tabular}

${ }^{\mathrm{a}}: p<0.05$ with respect to control

b: $p<0.01$ with respect to control

: $p<0.001$ with respect to control

Kidney tissue trace and major element concentrations in all of the subjects are shown in Table 6. The Ba concentration was significantly lower in high dose carmoisine group with respect to control $(p<0.05)$. In the low-dose tartrazine and carmoisine, and high-dose carmoisine groups $\mathrm{Cu}$ levels increased significantly compared to control $(p<0.05, p<0.001$ and $p<0.001$, respectively). Unlike, the Fe levels decreased significantly in low-dose tartrazine and low-dose carmoisine group,

with respect to control $(p<0.01)$. Mn concentrations were higher in low and high dose carmoisine group $(p<0.01$ and $p<0.05$, respectively).

Brain element levels were measured for the all of the subjects and these data were -presented in Table 7 . The $\mathrm{Al}$ concentrations were lower in the low-dose and high-dose tartrazine groups than the control $(p<0.001)$. Similarly Ba levels decreased significantly in the low-dose and highdose tartrazine groups when compared to control $(p<0.05$ 
and $p<0.01$, respectively). Fe concentrations significantly decreased in high-dose tartrazine, low-dose and high-dose carmoisine groups when compared to control $(p<0.05$, $p<0,001$ and $p<0.001$, respectively). Also in all experimental groups $\mathrm{Ga}$ levels were statically lower than the control $(p<0,05)$. For Be, Ca, Cr, Co, Mg, Mn and Se concentrations there were no statically significant differences in control and all experimental groups $(p>0.05)$.

\section{Discussion}

Azo compounds may reach the intestine directly after oral ingestion or through the bile after parenteral administration. It is subjected to the action of acid, digestive enzymes, and microflora (Amin et al., 2010). Azo dyes were catalyzed by azoreductases and peroxidases while semiquinone radicals and aromatic amines were the products of these reactions. Later, semiquinone radicals generated superoxide radicals, hydroxyl radicals, and $\mathrm{H}_{2} \mathrm{O}_{2}$. This possibly weakens cellular defense, thereby opening the door for a variety of oxidative stress-related disorders (Demirkol et al., 2012). Because of the large number of azo dyes and their widespread usage, research on their uptake and metabolization is important.

In this study, we did not observed any statistically significant changes in antioxidant vitamin levels in serum. Also there is no statistically important change in MDA and GSH contents of tissues. But we have some unique results about concentrations of trace and major elements in rats' liver, kidney and brain tissues exposed to the tartrazine and carmoisine. Especially iron and zinc contents have changed in a meaningful manner.

The present study revealed that rats consumed high and low doses of carmoisine had no any significant alteration in tissue MDA content, statistically. GSH plays a crucial role in protecting the intestines against oxidative damage that originates from possible toxic compounds in food. Besides, GSH is a necessary thiol compound that promotes normal development and function of the intestines (Moriarty-Craige and Jones 2004). Previous in vitro and in vivo studies show that aromatic amines were possibly responsible for the endotoxic and carcinogenic effects of azo dyes and that they significantly decreased GSH levels (Valentovic et al. 2002). Amin et al. (2010) showed that, when young male rats were given low (15 $\mathrm{mg} / \mathrm{kg} \mathrm{BW}$ ) and high (500 mg/kg BW) doses of tartrazine, the high dose decreases GSH levels in liver homogenates significantly, as compared to control. Siraki et al. (2002) found that incubation of hepatocytes with aromatic amines caused a decrease in the mitochondrial membrane potential before cytotoxicity ensued. Hepatocyte GSH was also depleted by all arylamines tested. Depletion of GSH puts cells at oxidative risks. The present study showed that consuming low and high doses of carmoisine and tartrazine changes the tissue GSH content. But this changeswere not statistically significant. We may conclude that tartrazine and carmoisine concentrations were not sufficient to change the GSH and MDA levels in tissues. Therefore, we surmise parameters as kind of dye, dose and consumption period didn't enough to change the levels of oxidative biomarkers. As known these dyes are safer dyes when it was used in a short time in ADI concentrations.

Vitamin A (retinol and $\beta$-carotene) and vitamin $\mathrm{E}$ (mostly $\alpha$-tocopherols, lipidsoluble antioxidant) can participate in the redox mechanism of the cell and neutralize reactive oxygen species(ROS) (Sayed et al., 2012). In this study consumption of low and high doses of tartrazine and carmoisine didn't affect the serum retinol, $\alpha$-tocopherol and $\beta$-carotene contents in comparison to control group (Table 2). Because of there isn't any research related with consumption of food colorants and its effect on antioxidant vitamin in serum, it is impossible to compare results with the literature. Therefore this study is a unique research to present relationship between artificial food colorants and antioxidant vitamins.

There is a shortage in the literatures dealing with bioelements so we have not been able to find adequate studies targeting bioelement levels in tissues with given food colorants. Due to inadequate research on bioelement levels in vital organs, this study is an important reference of which results certainly have great potential to be translated into important advances in public health. In this study, trace and major element levels of tissues are measured. Via this aspect this study is unique. According to Stevens et al. (2013) tartrazine may chelate iron as well as zinc. The degree of which artificial food color antschelate iron and other minerals needs further study. This study revealed that there is a diminish in iron levels of three tissues especially with consuming both doses of carmoisine. As we know, iron has crucial roles in most of biochemical reactions in body. Therefore this point is worthwhile to study in a detail manner.

In previous study showed that giving low and high doses of tartrazine have led to reductions in haemoglobin and haematocrit levels (Sharma et al., 2009). Our results, about iron, supported that anemia in mice may be related to iron deficiency. Thus, it should be considered that ingestion of foods containing food colorant for a long time may cause iron deficiency and anemia. This issue has great importance, especially for children.

Also by consuming carmoisine at both doses resulted with a reduction in zinc content of kidney, especially. Zinc acts as a cofactor in the metabolism of endogenous substances such as neurotransmitters, prostaglandins, melatonin, and dopamine, directly or indirectly (Arnold et al., 2010).Zinc deficiency causes various disorderssuch as hyperactivity and other behavioral changes in animals (Stevens et al., 2013). It is known that the xenobiotic material goes through the liver by blood and it is detoxified in hepatocytes. We surmise that zinc content is chelated by consumed dyes. Also biological membranes are particularly prone to the ROS effect, the peroxidation of unsaturated fatty acids in biological membranes leads to a decrease of membrane fluidity and disruption of membrane integrity and function (Amin et al., 2010). Because of this reason pumping and selecting activities of membranes may be affected and the level of bioelements may be altered in tissues. Although low dose tartrazine caused to reduce liver zinc content, high dose tartrazine cause to same effect in kidney.

Copper and iron can bind to artificial food colorants (Stevens et al., 2013). Because of this reason while we expecting a decrease in $\mathrm{Cu}$ level, differently we had an increased value in kidney tissue. This point is significant. 
Because an accumulation of copper in body leads to Wilson's disease with copper accumulation and cirrhosis of liver (Shazia et al., 2012). Aluminium and barium are essential trace elements. The levels of these elements in brain reduced by consuming high and low dose tartrazine. Also there is a significant increase in the calcium level in liver tissue with high dose carmoisine. But there isn't any information about relationship between these elements' levels and artificial food colorants in literature. Therefore, this study can be used as are ference for these points.

\section{Conclusion}

In conclusion, tartrazine and carmoisine affected the most important biochemical marker and biolement contents of vital organs e.g. liver, kidney and brain depend on consumption period, dose and kind of artificial colorants. Additional studies must be conducted to clarify the causes and the mechanisms of carmoisine because of its significant effects on vital organs as reducing iron and zinc or increasing copper and calcium content. Depletion of mentioned bioelements may result some disruptions in crucial pathways. Due to their indispensability for antioxidant defence mechanism and metabolic reaction chain, availability and quantity of them are vital. In addition to that it is necessary to create consumer awareness regarding the effects of this dyes and mention the type and concentration of each material added to food to prevent a variety of disorders beginning by weaker defence system and tissue damage.

\section{References}

[1] Amin,KA.,Hameid, II HA., AbdElsttar, AH., 2010. Effect of food azo dyes tartrazine and carmoisine on biochemical parameters related to renal, hepatic function and oxidative stress biomarkers in young male rats. Food and Chemical Toxicology. 48, 29942999.

[2] Arnold, LE., Disilvestro, RA., Bozzolo, D.,Bozzolo, H., Crowl L., Fernandez, S., Ramadan, Y., Thompson, S., Mo, X., Abdel-Rasoul, M., Joseph, E., 2010. Zinc for attention-deficit/ hyperactivity disorder: placebo-controlled double-blind pilot trial alone and combined with amphetamine. J Child Adolesc Psychopharmacol. 21, 1-19.

[3] Beutler, E., Dubon, O., Kelly, BM., 1963. Improved method for the determination of blood glutathione, J. Lab. Clin. Med. 61, 882888.

[4] Cemek, M., Buyukokuroğlu, ME., Buyukben, A., Aymelek, F., Ozcan, L. 2010. Effects of vitamin E and selenium on tissue bioelement status in organophosphate toxicity of rats. Pesticide Biochemistry and Physiology. 98, 9-18.
[5] Chequer, FMD., Lizier, TM., de Felicio, R., Zanoni, MVB., Debonsi, HM., Lopes, NP., Marcos, R., de Oliveira, DP., 2011a. Analyses of the genotoxic and mutagenic potential of the products formed after the biotransformation of the azo dye Disperse Red 1Toxicology in Vitro. 25, 2054-2063.

[6] Chequer, FMD., Dorta, DJ., de Oliveira, DP., 2011b. Azo dyes and their metabolites: does the discharge of the azo dye into water bodies represent human and ecological risks? In: Hauser PJ (ed) Advances in treating textile effluent. In Tech, Croatia. pp 28-48.

[7] Demirkol, O., Zhang, X., Ercal, N., 2012. Oxidative effects of Tartrazine (CAS No. 1934-21-0) and New Coccin (CAS No. 2611-82-7) azo dyes on CHO cells. J. Verbr. Lebensm. 7, 229-236.

[8] Gao, Y., Li, C.,Shen,J.,Yin, H., An, X., Jin, H., 2011. Effect of Food Azo Dye Tartrazine on Learning and Memory Functions in Mice and Rats, and the Possible Mechanisms Involved. Journal of Food Science. 76 (6), 125-129.

[9] Jain, SK., McVie, R.., Duett, J., Herbst, JJ., 1989. Erythrocyte membrane lipid peroxidase and glycolylated hemoglobin in diabetes, Diabetes. 38, 1539-1543.

[10] Mansour, H.B., Corroler, D., Barillier, D., Ghedira, K., Chekir, L., Mosrati, R., 2007. Evaluation of genotoxicity and pro-oxidant effect of the azo dyes: Acids yellow 17, violet 7 and orange 52, and of their degradation products by Pseudomonas putida mt-2. Food and Chemical Toxicology. 45, 1670-1677.

[11] Martinek, R., 1964. Method for determination of vitamin E (tocopherol) in serum, Clin. Chem. 10, 1078-1086.

[12] Moriarty-Craige,SE., Jones, DP., 2004. Extracellular thiols and thiol/disulfide redox in metabolism. Annu Rev Nutr. 24, 481-509.

[13] Moutinho, II D., Bertges, LC., Assis, RVC., 2007. Prolonged use of the food dye tartrazine (FD\&C Yellow n degrees 5) and its effects on the gastric mucosa of Wistar rats. Braz J Biol 67, 141-5.

[14] Sayed, H.M., Fouad, D., Ataya, F.S., Hassan, N.H., Fahmy, M.A., 2012. The modifying effect of selenium and vitamins $A, C$, and $E$ on the genotoxicity induced by sunset yellow in male mice. Mutation Research. 744, 145-153.

[15] Sharma, S., Goyal, R.P., Chakravarty, G., Sharma, A., 2008. Toxicity of tomato red, a popular food dye blend on male albino mice. Experimental and Toxicologic Pathology. 60, 51-57.

[16] Sharma, G., Gautam, D., Goyal, R.P., 2009. Tartrazine Induced Haematological and Serological Changes in Female Swiss albino Mice, Musmusculus. Pharmacology online 3: 774-788.

[17] Shazia, Q., Mohammad,ZH., Rahman, T., Shekhar, HU., 2012. Correlation of Oxidative Stress with SerumTrace Element Levels and Antioxidant Enzyme Status in Beta Thalassemia Major. Anemia. 2012, 7 pages.

[18] Siraki, A.G., Chan, T.S., Galati, G., Teng, S., O’Brien, P.J., 2002. $\mathrm{N}$-oxidation of aromatic amines by intracellular oxidases. Drug Metab. Rev. 34 (3), 549-564.

[19] Stevens,LJ.,Kuczek, T., Burgess, JR., Stochelski, MA., Arnold, LE., Galland, L., 2013. Mechanisms of behavioral, atopic, and other reactions to artificial food colors in children. Nutrition Reviews. 1 (5), 268-281.

[20] Suzuki, I., Katoh, N. 1990. A simple and cheap method for measuring serum vitamin A in cattle using spectrophototmeter, Jpn. J. Vet. Sci. 52, 1281-1283.

[21] Valentovic, MA, Ball, JG, Sun, H, Rankin, GO., 2002. Characterization of 2-amino-4,5-dichlorophenol (2A45CP) in vitro toxicity in renal cortical slices from male Fischer 344 rats. Toxicol. $172(2), 113-123$. 